\title{
AVALIAÇÃO DAS VIOLÊNCIAS E VALORES MORAIS
}

\author{
MANUEL TOSTAIN \\ JOËLLE LEBREUILLY \\ ROMAIN LEBREUILLY \\ TRADUÇÃO: Raphaël Maureau
}

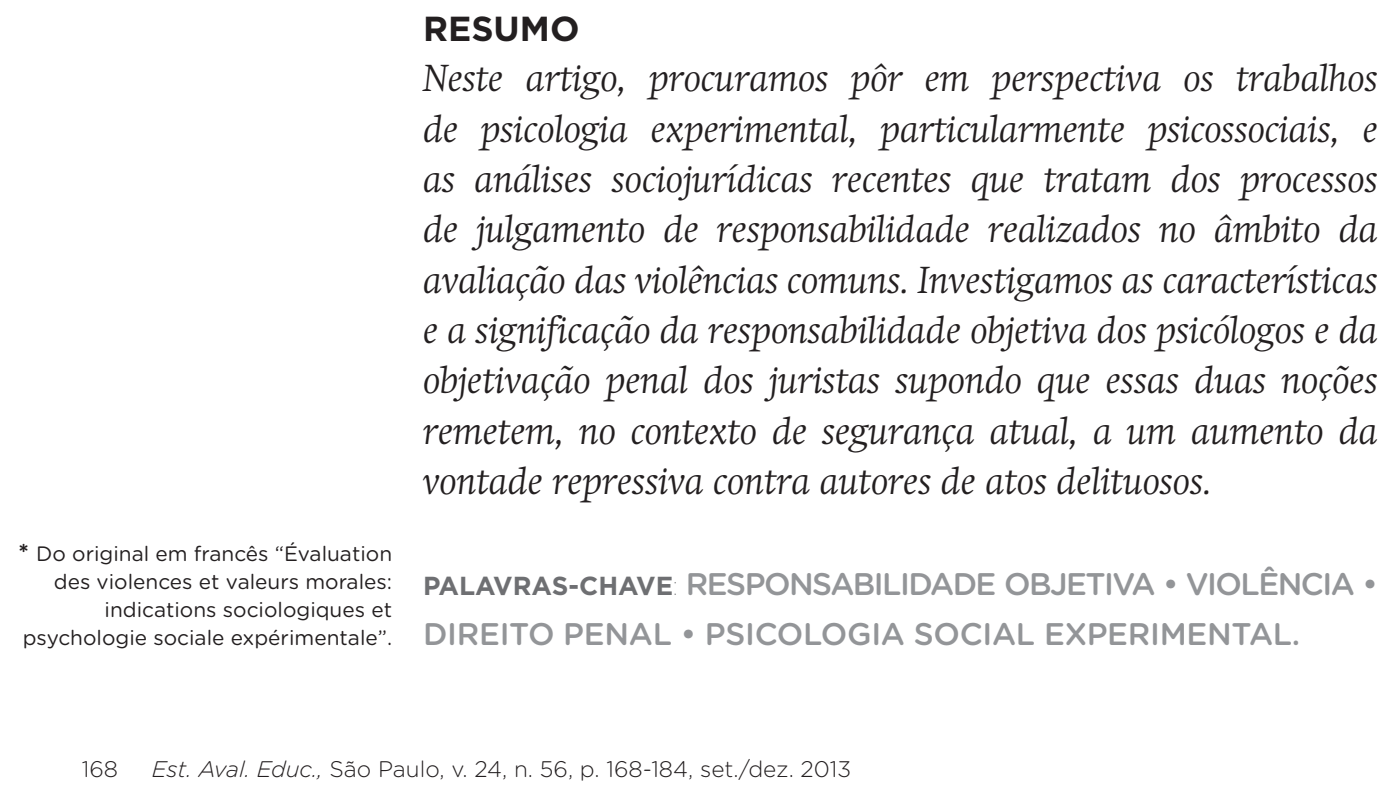

RESUMO

Neste artigo, procuramos pôr em perspectiva os trabalhos de psicologia experimental, particularmente psicossociais, e as análises sociojurídicas recentes que tratam dos processos de julgamento de responsabilidade realizados no âmbito da avaliação das violências comuns. Investigamos as características e a significação da responsabilidade objetiva dos psicólogos e da objetivação penal dos juristas supondo que essas duas noções remetem, no contexto de segurança atual, a um aumento da vontade repressiva contra autores de atos delituosos.

Do original em francês "Évaluation s violences et valeurs morales: 168 Est. Aval. Educ., São Paulo, v. 24, n. 56, p. 168-184, set./dez. 2013 


\section{RESUMEN}

En este artículo buscamos poner en perspectiva los trabajos de psicología experimental, particularmente los psicosociales, $y$ los análisis socio jurídicos recientes sobre procesos de juicios de responsabilidad realizados en el ámbito de la evaluación de las violencias comunes. Investigamos las características y la significación de la responsabilidad objetiva de los psicólogos y de la objetivación penal de los juristas, suponiendo que esas dos nociones remiten, en el contexto actual de seguridad, a un aumento de la voluntad represiva contra autores de actos delictivos.

PALABRAS CLAVE RESPONSABILIDAD OBJETIVA • VIOLENCIA •

DERECHO PENAL・PSICOLOGÍA SOCIAL EXPERIMENTAL.

\section{ABSTRACT}

We have tried to put into perspective experimental psychology works, particularly psychosocial ones, and recent socio-legal analyses dealing with responsibility trials regarding the assessment of common acts of violence. We investigated the characteristics and the significance of the psychologists' objective responsibility and the criminal lawyers' penal objectives assuming that these two notions refer, in the current security context, to an increased desire of repression of perpetrators of criminal acts.

KEYWORDS OBJECTIVE RESPONSIBILITY - VIOLENCE • CRIMINAL LOW • EXPERIMENTAL SOCIAL PSYCHOLOGY. 


\section{INTRODUÇÃO}

Os últimos anos foram marcados por um aumento de sensibilidade em relação à violência social, e essa evolução veio acompanhada de uma política mais repressiva no nível penal (LAGRANGE, 2003). Este artigo tem como objetivo apresentar um programa de pesquisas experimentais realizadas com base em uma reflexão sobre as evoluções atuais do direito penal. Nesse contexto, trataremos de confrontar as abordagens cognitivas nos processos de julgamentos visando à atribuição de responsabilidade com as análises sociojurídicas que evidenciam um movimento em favor do que os juristas chamam de objetivação penal. Esse movimento de objetivação penal reflete um aumento, nas sociedades contemporâneas, incluindo a francesa, de valores morais centrados na punição, na retribuição.

A responsabilidade, isto é, o fato de ter de prestar contas, de responder a esses atos (FINCHAM; JASPARS, 1980; VILLEY, 1989) e, quando necessário, receber uma sanção (FOUCONNET, 1920), é um elemento fundamental do direito. Não se deve, no entanto, processar penalmente alguém considerado irresponsável. 
Em psicologia, desde os trabalhos pioneiros de Piaget (1932) sobre o julgamento moral entre as crianças, é clássico distinguir, com base em uma perspectiva cognitiva, a responsabilidade objetiva da responsabilidade subjetiva, a primeira referindo-se aos julgamentos de responsabilidade e à sanção, relacionados principalmente à relevância das consequências objetivas (materiais ou humanas) dos delitos cometidos, a segunda referindo-se ao estado mental do autor do ato e suas intenções para determinar sua responsabilidade e sua sanção (BORDEL, 2002; TOSTAIN, 1999). De um ponto de vista objetivo da responsabilidade, a sanção é proporcional à gravidade das consequências, e não se leva muito em conta a intencionalidade do autor do ato (que ele o tenha cometido, por exemplo, propositalmente ou não). Já de um ponto de vista subjetivo da responsabilidade, a sanção é determinada em função do que fez voluntariamente o autor do ato e, nesse caso, a responsabilidade não leva tanto em conta a gravidade das consequências objetivas involuntárias do ato.

As pesquisas experimentais em psicologia social do desenvolvimento mostram que a responsabilidade objetiva é muito presente em crianças pequenas, de até 7,8 anos de idade, que tendem a focalizar as consequências materiais e visíveis do ato; e que, com a idade, os indivíduos tendem a se referir principalmente à responsabilidade subjetiva, analisando o estado de espírito do autor no momento de seu ato, para determinar seu grau de responsabilidade e o nível da sanção (TOSTAIN; LEBREUILLY, 2005a; TURIEL, 1998).

Em um nível sociológico, autores como Durkheim (1900), Fauconnet (1920) ou Foucault (1975) destacarão uma evolução, com certas considerações similares, do direito penal, caracterizada por um fenômeno de subjetivação penal. E assim, quanto mais nos aproximamos do período moderno, mais a determinação da pena se baseia nas intenções dos transgressores. Para explicar tal fenômeno, esses autores evocarão, particularmente, o desenvolvimento do individualismo que leva a considerar cada vez mais as motivações e as condições psicológicas dos sujeitos infratores. 
Em última análise, considera-se, geralmente, que a responsabilidade objetiva diminui com a idade e que essa diminuição se acentua em nossas sociedades contemporâneas.

No entanto, alguns juristas (ENGEL, 1995; GARAPON; GROS; PECH, 2001; MAYNAUD, 2003; VINEY, 2000) apontam, nos anos recentes, um fenômeno inverso de objetivação penal ou de diminuição da subjetivação penal. Daremos aqui dois exemplos dessa objetivação penal. No primeiro, constata-se um desenvolvimento, em relação ao código penal, do que chamamos de delitos não intencionais. Esses delitos minimizam os aspectos subjetivos da responsabilidade (capacidades mentais, caráter voluntário do ato) e estabelecem escalas de pena em função da relevância dos danos materiais ou corporais. Trata-se de infrações cometidas por negligência, por não cumprimento de uma norma de segurança, que provocam uma consequência negativa involuntária. Exemplo de delito não intencional: deixar solto um cachorro perigoso que causa ferimentos em uma pessoa, ou ultrapassar o sinal vermelho e atropelar um pedestre. Nesse último caso, se o fato de ultrapassar o sinal vermelho é intencional, trata-se de uma infração do código de trânsito, a consequência, ferir o transeunte, não é voluntária e constitui um delito não intencional: trata-se, portanto, de um delito involuntário contra a integridade física da pessoa. Segundo exemplo: de um ponto de vista objetivo, a questão da capacidade mental, do estado psicológico do autor do ato, é obviamente muito relevante, pois é com base nesse tipo de análise que se estabelece a responsabilidade penal ou, ao contrário, a irresponsabilidade penal do indivíduo acusado. No entanto, constatou-se nos últimos anos que a porcentagem de sujeitos considerados penalmente irresponsáveis caiu. O que isso significa? Não significa que o número de indivíduos acusados apresentando distúrbios psicológicos graves tenha diminuído. Nem que se tenha prestado menos atenção à questão da presença de distúrbios psicológicos ou de elementos subjetivos. Isso significa que os elementos subjetivos influem menos hoje do que anteriormente na responsabilidade penal e são cada vez menos considerados como motivos de irresponsabilidade penal. Em última análise, pode-se dizer resumidamente que há 
um conjunto de fenômenos que fazem com que as sanções se tornem mais automáticas, e que estas estejam mais relacionadas à gravidade dos atos do que à intencionalidade dos autores acusados.

Para explicar esse fenômeno de objetivação penal, podemos adiantar que ele conduz a atitudes mais punitivas em relação aos delitos. De fato, enquanto a responsabilidade subjetiva possibilita a consideração de circunstâncias atenuantes mencionando a não intencionalidade infratora - o que representa um ponto problemático - do ponto de vista da responsabilidade objetiva, a punição é mais sistemática, pois se baseia na relevância do prejuízo material ou corporal.

Nesse contexto, gostaríamos de evocar aqui duas pesquisas envolvendo a questão da responsabilidade objetiva. A primeira tem o intuito de mostrar que, contrariamente ao que a literatura psicológica indica, a responsabilidade objetiva não se faz necessariamente menos presente entre os adultos do que entre as crianças. A segunda tem como objetivo evidenciar que os processos judiciais podem apresentar alterações profundas em função da relevância das consequências objetivas dos delitos.

\section{ESTUDO 1}

No primeiro estudo (para mais detalhes, ver TOSTAIN; LEBREUILLY, 2005b), apresentamos a 120 estudantes de 18 a 23 anos de idade e a 120 crianças de 7-8 anos duas séries de quatro delitos trazendo consequências não intencionais e que, em termos de responsabilidade, cruzavam dimensões subjetivas (com duas modalidades) e dimensões objetivas (também com duas modalidades). Na primeira série, manipulou-se a natureza intencional da ação inicial (aspecto subjetivo) e a importância de sua consequência (aspecto objetivo): tratava-se do caso de um automobilista que ultrapassou o sinal vermelho, seja propositalmente (intencionalidade forte) ou involuntariamente (intencionalidade fraca). ${ }^{1} \mathrm{Na}$ ocasião, um pedestre que atravessava a rua no mesmo momento, e que não foi visto pelo automobilista, ficou ferido levemente (consequência objetiva leve) ou

o sinal estava vermelho. 
morreu (consequência objetiva grave). Na segunda série de delitos, manipulou-se novamente a relevância objetiva das consequências e variou-se a condição mental dos autores dos delitos (aspecto subjetivo). Concretamente, tratava-se de um incêndio causado, seja por um indivíduo cujos especialistas alegaram a presença de distúrbios psiquiátricos (um piromaníaco no sentido estrito, intencionalidade fraca), seja por um indivíduo considerado normal pelos especialistas (intencionalidade forte). Em função das versões, esse incêndio causou involuntariamente, seja ferimentos leves em um indivíduo (consequência objetiva leve), seja a morte desse indivíduo (consequência objetiva grave).

Em seguida, para cada uma das quatro histórias de cada série, os sujeitos tiveram de avaliar a gravidade do ato inicial, dizer se era o caso de punir ou não o autor do ato e avaliar a severidade (o rigor) da sanção. Para isso, os sujeitos utilizaram escalas de 8 pontos do tipo Lickert (indicando o grau de gravidade ou severidade: 1 nada grave ou nada severo; 8: muito grave ou muito severo).

Foram levantadas duas hipóteses: a primeira é que a sensibilidade à dimensão objetiva da responsabilidade seria tão considerável entre os adultos quanto entre as crianças; a segunda, que a responsabilidade objetiva estaria associada a atitudes mais punitivas do que a responsabilidade subjetiva.

\section{RESULTADOS}

Com relação à primeira série concernindo ao automobilista que ultrapassou o sinal vermelho, notou-se que o percentual de sujeitos que recomendaram uma sanção foi bastante elevado (entre 78 e $100 \%$ ). 
TABELA 1 - Porcentagem de crianças e adultos que se declararam favoráveis a uma sanção para cada uma das versões apresentadas (1ª série)

\begin{tabular}{|c|c|c|c|c|}
\hline \multicolumn{3}{|c|}{$\begin{array}{c}\text { AUTOMOBILISTA ULTRAPASSA SINAL VERMELHO } \\
\text { E ATROPELA PEDESTRE (1ः SÉRIE) }\end{array}$} & \multicolumn{2}{|c|}{ FAVORÁVEL A UMA SANÇÃO } \\
\hline VERSÃO & INTENCIONALIDADE & $\begin{array}{l}\text { CONSEQUENNCIA } \\
\text { OBJETIVA }\end{array}$ & CRIANÇAS & ADULTOS \\
\hline 1 & Forte (voluntária) & Grave & $98 \%$ & $98 \%$ \\
\hline 2 & Forte (voluntária) & Leve & $95 \%$ & $100 \%$ \\
\hline 3 & Fraca (involuntária) & Grave & $80 \%$ & $95 \%$ \\
\hline 4 & Fraca (involuntária) & Leve & $78 \%$ & $93 \%$ \\
\hline
\end{tabular}

Fonte: Elaboração dos autores.

Constatou-se também que para as versões que concerniam ao automobilista que havia ultrapassado involuntariamente o sinal vermelho (intencionalidade fraca) o número de adultos que se declararam favoráveis a uma sanção foi significativamente maior que o número de crianças (aplicação do teste estatístico qui-quadrado apontou diferença significativa).

Em relação à severidade da sanção, obtivemos os resultados esperados. Por um lado, o automobilista recebe punições mais severas quando ultrapassa o sinal propositalmente (intencionalidade forte) ou quando o delito causa a morte da vítima (consequência objetiva grave).

FIGURA 1 - Nota de severidade de acordo com a natureza voluntária ou involuntária da ação inicial e a relevância das consequências objetivas ( $1^{\text {a }}$ série)

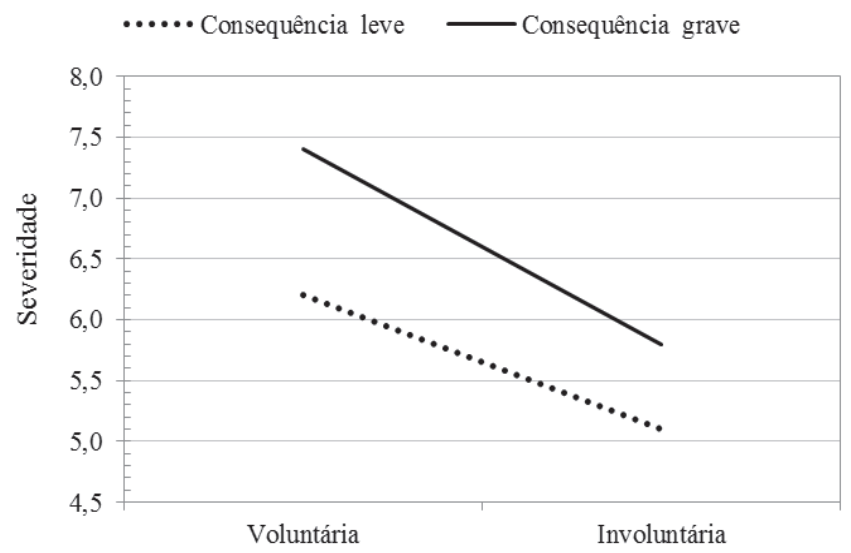

Fonte: Elaboração dos autores. 
Entretanto, e esse é um ponto importante, não houve diferença em relação à idade: as crianças se mostraram tão sensíveis quanto os adultos aos aspectos subjetivos e objetivos das diferentes versões. Os adultos, em particular, tendem a desconsiderar o fato de que, em certos casos, o automobilista havia ultrapassado involuntariamente o sinal vermelho, ou que foi atrapalhado pelo passageiro que o acompanhava. Em outras palavras, esses aspectos que, em termos subjetivos, podem ser associados a uma minimização da punição (intencionalidade leve) não foram mais diferenciados pelos adultos do que pelas crianças.

Para a segunda série de delitos (atos incendiários), a porcentagem de sujeitos que se declararam favoráveis à atribuição de uma sanção é igualmente muito elevada e gira em torno de $92 \%$.

TABELA 2 - Porcentagem de crianças e adultos que se declararam favoráveis a uma sanção para cada versão apresentada ( $2^{\mathrm{a}}$ série)

\begin{tabular}{l|c|l|c|c}
\hline \multicolumn{3}{c}{ ATO INCENDIÁRIO (2" SÉRIE) } & \multicolumn{2}{c}{ FAVORÁVEL A UMA SANÇÃO } \\
\hline VERSÃO & INTENCIONALIDADE & $\begin{array}{l}\text { CONSEQUÊNCIA } \\
\text { OBJETIVA }\end{array}$ & CRIANÇAS & ADULTOS \\
\hline 1 & Fraca (distúrbio psiquiátrico) & Grave & $80 \%$ & $93 \%$ \\
\hline 2 & Fraca (distúrbio psiquiátrico) & Leve & $83 \%$ & $91 \%$ \\
\hline 3 & Forte (pessoa "normal") & Grave & $98 \%$ & $98 \%$ \\
\hline 4 & Forte (pessoa "normal") & Leve & $98 \%$ & $91 \%$ \\
\hline
\end{tabular}

Fonte: Elaboração dos autores.

Com relação à severidade da sanção, foram constatados os mesmos efeitos esperados na $1^{\text {a }}$ série: mais severidade em caso de morte da vítima do que em caso de ferimento, mais severidade para o indivíduo declarado normal do que para o indivíduo com distúrbios psiquiátricos. 
FIGURA 2 - Severidade da sanção de acordo com a condição mental do autor do delito e com a relevância das consequências objetivas ( $2^{\mathrm{a}}$ série)

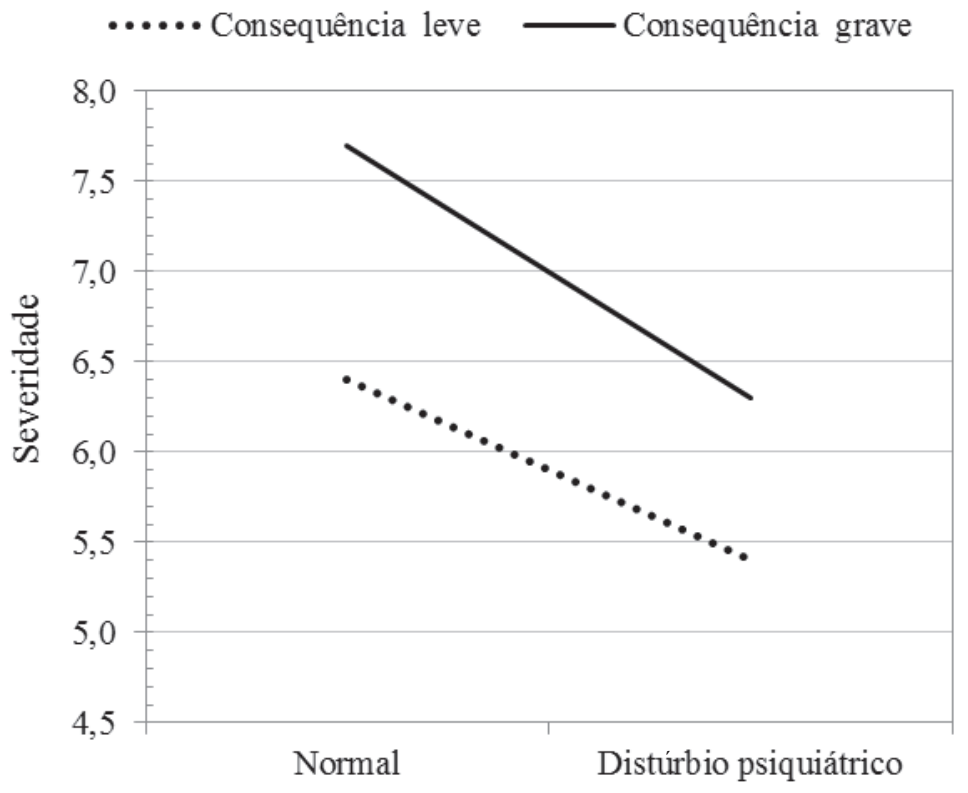

Fonte: Elaboração dos autores.

Ademais, e esse ponto é igualmente importante, não houve diferença em relação à idade: as crianças e os adultos mostraram-se igualmente sensíveis aos aspectos subjetivos e objetivos. Aqui, concretamente, percebe-se que os adultos dão pouca importância à presença de distúrbios psiquiátricos para reduzir a sanção.

Em seguida, procuramos investigar se a responsabilidade objetiva está associada a atitudes mais punitivas do que a responsabilidade subjetiva. Para tal, recorremos ao critério clássico de Piaget (1932) no qual um sujeito é pautado pela responsabilidade objetiva quando é mais severo com o autor de uma ação inicial involuntária provocando consequências graves do que com o autor de uma ação voluntária provocando consequências leves, ou então pela responsabilidade subjetiva, se procede da maneira inversa. Para cada série, definimos sujeitos RO (centrados na responsabilidade objetiva) e sujeitos RS (centrados na responsabilidade subjetiva). Por exemplo, para a $1^{\mathrm{a}}$ série, um sujeito era considerado RO se havia dado uma sanção mais elevada para o motorista que, 
perturbado pelo passageiro que o acompanhava, não percebeu o sinal vermelho e ocorreu o falecimento da vítima (intencionalidade leve, consequência objetiva grave) do que para o motorista que ultrapassou propositalmente o sinal vermelho e a vítima ficou ferida levemente (intencionalidade forte, consequência objetiva leve). Em seguida, calculamos a nota média de severidade atribuída por cada sujeito RO e RS nas quatro versões de cada série. Depois, analisamos a variância.

Duas coisas foram constatadas. Por um lado, que houve a mesma proporção de sujeitos declarados RO entre as crianças e os adultos. Por outro, que as notas médias de severidade de sujeitos RO foram significativamente maiores que as de sujeitos RS, tanto na $1^{\text {a }}$ como na $2^{\text {a }}$ série.

TABELA 3 - Nota média de severidade para cada série, segundo o perfil RO ou RS dos sujeitos

\begin{tabular}{l|c|c}
\hline PERFIL DO SUJEITO & 1ª SÉRIE & 2a SÉRIE \\
\hline RO & 6,9 & 6,5 \\
\hline RS & 5,9 & 5,6 \\
\hline
\end{tabular}

Fonte: Elaboração dos autores.

Em última análise, esses resultados mostram, em primeiro lugar, que os adultos e as crianças são, mesmo que por razões sem dúvida diferentes, igualmente sensíveis à dimensão objetiva da responsabilidade; e, em segundo lugar, que a responsabilidade objetiva corresponde a uma orientação mais punitiva do que a responsabilidade subjetiva.

\section{ESTUDO 2}

Vimos que os adultos são sensíveis à responsabilidade objetiva. Nesse segundo estudo (para mais detalhes, ver TOSTAIN; LEBREUILLY, 2008), nosso interesse eram os efeitos da relevância das consequências objetivas sobre os julgamentos de responsabilidade. De um ponto de vista racional, alguns trabalhos relacionados à psicologia social experimental (para uma síntese, ver ALICKE, 2000) mostram que a determinação 
da responsabilidade e a atribuição de sanções a um indivíduo decorrem de um processo ordenado por etapas. Assim, procura-se identificar, em primeiro lugar, se existe uma ligação causal entre a ação do indivíduo e as consequências constatadas (a pessoa está materialmente na origem da consequência?). Se essa condição é confirmada, estima-se o grau de intencionalidade desse indivíduo (ele agiu propositalmente?), o que permite avaliar seu nível de responsabilidade. Em seguida, a decisão de considerar a ação condenável ou não e de atribuir sanções é modulada pela presença ou não de pedidos de desculpas e de justificativas aceitáveis. Para simplificar, o esquema parte da causalidade, vai em direção à responsabilidade e termina com a sanção. Supõe-se, portanto, a existência de ligações e correlações entre essas três dimensões. Isso sempre acontece, especialmente quando as consequências objetivas dos delitos e sua gravidade são fortes. Nesse caso, a emoção é forte e a vontade de sanção também. Não se pode imaginar, então, que não é a responsabilidade que orienta o processo, mas sim a sanção (FAUCONNET, 1920). Foi o que nós procuramos investigar apresentando fatos reais que trazem consequências objetivas mais ou menos graves.

Para isso, apresentamos a 250 estudantes do primeiro ano de ciências humanas dois casos variantes em termos de gravidade. O primeiro caso diz respeito a um episódio de excesso de velocidade que provocou a colisão de dois veículos ocasionando, numa primeira versão, o falecimento de duas crianças (consequência objetiva grave) e, numa segunda versão, somente ferimentos (consequência objetiva leve). $\mathrm{O}$ segundo caso diz respeito a um enfermeiro que, ao puxar com força um lençol do leito de um paciente, provocou, na primeira versão, ferimentos no paciente (consequência objetiva leve) e, na segunda versão, a queda do paciente e seu falecimento (consequência objetiva grave). No segundo caso, colocou-se em questão a intencionalidade: o enfermeiro quis ou não machucar o paciente?

Cada sujeito leu apenas um único caso em sua versão grave ou leve em relação às consequências objetivas. Em seguida, teve de avaliar a relação de causalidade entre a ação do autor do ato e a consequência (em que medida o ato 
explica a consequência negativa constatada). Depois, teve de avaliar, no primeiro caso, o caráter negligente da conduta do condutor do veículo e, no segundo caso, o caráter intencional do ato (o enfermeiro quis ou não machucar?). Em seguida, para os dois casos, o sujeito estimou o grau de responsabilidade do autor do ato. Essas avaliações de causalidade, negligência (ou intencionalidade) foram feitas com base em uma escala do tipo Likert de 1 a 10 pontos (1: nada culpado e 10: totalmente culpado). Em seguida, o sujeito teve de atribuir uma sanção com base em uma escala: 0 meses a 10 anos de prisão. Para a metade dos sujeitos, as tarefas foram efetuadas em ordem inversa: a estimação da sanção ocorria em primeiro lugar, ou seja, antes das estimações de causa, negligência (ou intencionalidade) e de responsabilidade (ver OBERLÉ; GOSLING, 2004 para os detalhes e as hipóteses teóricas relacionadas a esse tipo de procedimento em que se manipula a ordem do processo de julgamento).

\section{RESULTADOS}

Quando as consequências objetivas são leves (apenas ferimentos), constata-se uma correlação entre os diferentes julgamentos e a sanção, e que a ordem das tarefas (atribuição de sanção no início ou no final) não modifica essa relação. Portanto, foram obtidos resultados que estão de acordo com um ponto de vista racional, no qual a sanção é determinada em função do nível de responsabilidade e a responsabilidade é determinada em função da intencionalidade. No entanto, quando as consequências objetivas são graves (falecimento das crianças ou do paciente), a ordem das tarefas intervém. Quando a sanção é determinada no final do julgamento (ordem normal), admitindo-se a correlação entre a causalidade, a intencionalidade e a responsabilidade, essas três dimensões não são nada correlatas com a sanção. Em outras palavras, no caso de consequências graves, a sanção não é determinada em função da responsabilidade, mas é independente. No entanto, quando a sanção foi determinada antes (ordem inversa), constatou-se correlação entre todas as dimensões. Nesse caso, já que na ordem normal (sanção determinada no final) não havia correlação, tem-se a impressão de que há um meca- 
nismo de justificação da sanção: a sanção determinada previamente é justificada com base no ajuste do nível de sua casualidade, intencionalidade e responsabilidade. Em última análise, em caso de consequências graves, tudo se passa como se a sanção tivesse uma dinâmica própria (sem correlação na ordem normal), e os julgamentos de responsabilidade poderiam, contudo, ser correlatos se as situações tornassem possível a racionalização da sanção, o que ocorre no caso em que a ordem é invertida.

\section{CONCLUSÃO}

Segundo nosso ponto de vista, esses dois estudos mostram duas coisas. Por um lado, que os adultos são muito sensíveis à dimensão objetiva da responsabilidade. Por outro, que os processos de julgamento são alterados e modificados por essa dimensão objetiva (eles não são, necessariamente, os mesmos em caso de consequências leves e consequências graves. Cf. estudo 2). A pergunta final é a seguinte: o que significa essa sensibilidade à dimensão objetiva? Se entre as crianças isso revela, principalmente, um aspecto realista, a influência da materialidade dos fatos e a dificuldade em definir a intenção do autor do ato criminoso (cf. trabalhos de Piaget), entre os adultos podemos supor que essa sensibilidade à dimensão objetiva revela três dinâmicas: 1) ela revela valores morais mais punitivos: por um lado, de acordo com o primeiro estudo, os sujeitos centrados na dimensão objetiva (sujeitos RO) são mais severos que os sujeitos centrados na dimensão subjetiva (sujeitos RS); por outro lado, no segundo estudo, vimos que, no caso de consequências objetivas graves, o processo parece dar ênfase na sanção; 2) ela revela uma vontade de responsabilização dos atores sociais. De fato, contrariamente à responsabilidade subjetiva que autoriza uma minimização da pena (em função do grau de intencionalidade do autor do ato), e até mesmo uma anulação da pena (em caso de incapacidades mentais), na responsabilidade objetiva, quando se tem danos materiais ou humanos, a responsabilidade é atribuída e a sanção é automática (a intensidade da sanção é calcada 
sobre a relevância dos danos constatados). Em outras palavras, não há escapatória em relação à responsabilidade objetiva; 3) ela revela igualmente uma maior consideração em relação às vítimas. De fato, evocar a dimensão objetiva é levar em consideração não o que aconteceu em decorrência do ato do autor (e nós nos perguntamos sobre a intencionalidade inicial do autor do ato, seu estado mental, ou seja, aspectos subjetivos), mas o que esse ato provocou, suas consequências, o dano causado à vítima, o sofrimento que o ato causou. Isso explica, aliás, no caso de consequências objetivas graves, que não há, necessariamente, uma ligação direta entre o nível de responsabilidade e a sanção. Nesse caso, a punição não é determinada apenas pela intencionalidade do autor do ato, mas também pelo o que ele provocou mais ou menos voluntariamente como dano para as vítimas.

Em última análise, a responsabilidade objetiva estudada por psicólogos com base em um ponto de vista experimental, sua versão social, e a objetivação penal dos juristas manifestam um mesmo fenômeno: a tendência a adotar valores morais repressivos. Nesse sentido, essa dimensão objetiva da responsabilidade está de acordo com as tendências de segurança atuais. ${ }^{2}$

\section{REFERÊNCIAS}

ALICKE, M. D. Culpable control and the psychology of blame. Psychological Bulletin, v. 126, n. 4, p. 556-574, 2000.

BORDEL, S. Les dimensions objectives et subjectives du jugement de responsabilité. 2002. Thèse non publiée - University of Rennes 2, France, 2002.

CASTEL, R. L'insécurité sociale. Qu'est-ce qu'être protégé? Paris: Seuil, 2003.

DURKHEIM, E. Deux lois de l'évolution pénale. L’Année Sociologique, p. 65-95, 1900.

ENGEL, L. La responsabilité en crise. Paris: Hachette, 1995.

FAUCONNET, P. La responsabilité. Paris: Felix Alcan, 1920.

FINCHAM, F. D.; JASPARS, J. M. Attribution of responsibility: from man the scientist to man as lawyer. In: BERKOWITZ, L. (Ed.), Advances in Experimental Social Psychology, v.13. New York: Academic, 1980. p. 81-138.

FOUCAULT, M. Surveiller et puni: naissance de la prison. Paris: Gallimard, 1975. 
GARAPON, A.; GROS, F.; PECH, T. Et ce sera justice: Punir en démocratie. Paris: Odile Jacob, 2001.

LAGRANGE, H. Demandes de sécurité. Paris: Seuil, 2003.

MAYNAUD, Y. Violences involontaires et responsabilité pénale. Paris: Dalloz, 2003.

OBERLÉ, D.; GOSLING, P. Intention, responsabilité, sanction : L'intention est-elle un préalable ou une justification de la sanction? In: BEAUVOIS, J. L.; JOULÉ, R. V.; MONTEIL, J. M. (Ed.), Perspectives Cognitives et Conduites Sociales, v. 9. Rennes: Universitaires de Rennes, 2004. p. 271-192.

PIAGET, J. Le jugement moral chez l'enfant. Paris: Félix Alcan, 1932.

TOSTAIN, M. Psychologie, morale et culture. L'évolution de la morale de l'enfance à l'âge adulte. Grenoble: Universitaires de Grenoble, 1999.

TOSTAIN, M.; LEBREUILLY, J. Représentations de la délinquance chez des enfants de 5 à 10 ans. Enfance, v. 4, 2005a.

Les adultes sont-ils réellement moins sensibles à la dimension objective de la responsabilité que les enfants? Revue Internationale de Psychologie Sociale, v. 18, n. 4, p. 99-123, 2005 b.

Rational model and justification model in « outcome bias ». European Journal of Social Psychology, v. 38, n. 2, p. 272-279, 2008.

TURIEL, E. The development of morality. In: DAMON, W.; EISENBERG, N. (Ed.), Handbook of Child Psychology, v. 3. New York: John Wiley \& Sons, 1998. p. 863- 932.

VILLEY, M. Esquisse historique sur le mot responsable. In: BOULET-SAUTEL, M. et al. La responsabilité à travers les âges. Paris: Economica, 1989. p. 75-88.

VINEY, G. La responsabilité et ses transformations (responsabilités civile et pénale). In: MICHAUD, Y. (Ed.), L'université de tous les savoir: qu'est-ce que l'humain?, v. 2. Paris: Odile Jacob, 2000. p. 144-156.

\section{MANUEL TOSTAIN}

Professor de Psicologia Social do Centre d'Études et de Recherche sur les Risques et les Vulnérabilités da Université de Caen Basse-Normandie (UCBN), França manuel.tostain@unicaen.fr

\section{JOËLLE LEBREUILLY}

Mestre de conferências em Psicologia Social. Professora assistente de Psicologia Social do Centre d'Études et de Recherche sur les Risques et les Vulnérabilités da Université de Caen Basse-Normandie (UCBN), França joelle.lebreuilly@unicaen.fr 


\section{ROMAIN LEBREUILLY}

Pesquisador associado à Université de Caen Basse-Normandie

(UCBN), França

r.lebreuilly@free.fr 